\title{
Degradation study of BPA-containing plastics in water samples collected from an urban reservoir
}

\begin{abstract}
Water pollution is a significant problem worldwide, particularly in Brazil where the majority of urban populations rely on drinking water from surface water reservoirs. The accumulation of plastic debris, such as polycarbonate blends, in reservoirs and other waterways is a public health issue because of health and environmental concerns associated with their chemical degradation. A compound commonly found in plastics, 2,2-bis(4-hydroxyphenyl)propane (bisphenol-A; BPA), has become a serious environmental problem due to its release in water and its estrogen-like properties. This paper focuses on understanding the degradation process of two types of plastics containing BPA, polypropylene (PP) and poly(lactic acid) (PLA), in surface waters. The strength of the chemical binding of BPA to PP and PLA was examined using thermogravimetric analysis (TGA) and Fourier transform infrared (FTIR) spectroscopy. Release of BPA from both types of plastics was determined in surface water samples collected from the Billings Reservoir, the largest source of drinking water of Sao Paulo residents. The results show that BPA bound to PP-based plastics is released more rapidly into surface waters than that bound to PLA-based plastics.
\end{abstract}

Volume 2 Issue 3 - 2018

\author{
Derval dos Santos Rosa,' Larissa \\ Nunes,' Viviane do Nascimento \\ Bianchi, ${ }^{2}$ Carlos Eduardo Rogrigues \\ Gracio, ${ }^{2}$ Elizabete Campos de Lima ${ }^{2}$ \\ 'Center for Engineering and Applied Social Sciences, Federal \\ University of ABC, Brazil \\ ${ }^{2}$ Center for Natural and Human Sciences, Federal University of \\ ABC, Brazil
}

Correspondence: Elizabete Campos de Lima, Center for Natural and Human Sciences, Federal University of ABC, Brazil, Tel +55 I| 4996 0 I88/0046, Email elizabete.lima@ufabc.edu.br

Received: February 09, 2018 | Published: May 29, 2018

Keywords: BPA degradation, PLA, PP, urban water reservoir, biodegradable polymer

\section{Introduction}

Contamination of water resources is one of the main environmental problems nowadays, and the concern with micro pollutants, i.e., substances that are present in concentrations in the order of $\mu \mathrm{gL}^{-1}$ and $\mathrm{ngL}^{-1}$, has increased significantly in recent years. ${ }^{1,2}$ Despite being detected in low concentrations, micro pollutants are capable of causing serious effects to biota. Among the substances that can be classified as micro pollutants, we highlight 2,2-bis(4-hydroxyphenyl)propane (BPA), a substance that has estrogenic activity. BPA has become ubiquitous in the environment over the past 80 years because of its presence in a wide variety of products, including food and beverage packaging, flame retardants, adhesives, construction materials, electronic components, and paper coatings. ${ }^{3}$ BPA is a non-steroidal xenoestrogen that exhibits approximately $1 / 10000$ th of the activity of estradiol. $^{4}$

The estrogenic effects of BPA were initially reported by Dodds \& Lawson. ${ }^{5}$ Recent studies indicate that BPA may be as effective as estradiol in triggering certain receptor responses and may act as an androgen receptor antagonist. ${ }^{6}$ There are an impressive number of studies on the effects of BPA exposure on laboratory animals, but few studies are dealing with the effects of BPA on wild species in field or laboratory settings. ${ }^{3} \mathrm{BPA}$ is considered a pseudo-persistent compound: although short-lived, it is ubiquitous in the environment because of its continuous release. ${ }^{7}$ The release of BPA into the environment may occur during chemical manufacturing, transportation, or processing as well as via discharge of effluents from municipal wastewater treatment plants, leaching from sanitary landfills, combustion of household waste, and leaching from plastics. Some researchers were unaware that BPA could leach from plastics until $1993,{ }^{8}$ and subsequent studies have confirmed that BPA can also leach from polycarbonates and epoxy resins. Several studies indicate that BPA concentrations in various aqueous media, including surface water, saltwater, and groundwater, have increased in recent years. ${ }^{7}$ However, BPA leaching is much faster in salt water than in freshwater as its bioavailability increases with salinity. ${ }^{9}$ The half-life of BPA in surface waters is 150 days. ${ }^{10}$ However, due to leaching and its inadequate disposal, BPA is considered persistent in the environment.

BPA is present in a variety of products, such as soda cans, water bottles, plastic cups, and food packaging. Polypropylene (PP) is a plastic material widely used in various industrial applications; however, PP has poorer mechanical strength and thermal stability than most engineering polymers. To overcome these limitations, BPA polycarbonate can be incorporated into PP. ${ }^{11}$ Poly(lactic acid) (PLA) also has limitations and the addition of BPA polycarbonate can be beneficial in this regard. ${ }^{12}$ PP and PLA are widely used in packaging and can generate BPA and its derivatives during thermal degradation. Metal water bottles, especially those made of aluminum, are coated with epoxy resins that may contain BPA to combat corrosion. Food stored in glassware may not be free of exposure to BPA because the metal lids typically used in this type of storage often have an anticorrosive epoxy coating that contains BPA. Furthermore, plastic bowls and other containers used for cooking in microwave oven may release BPA during heating. ${ }^{13}$ This study evaluates the release of BPA incorporated into two different formulations of plastic materials, PLA, a biodegradable polyester, and PP, a polyolefin, as well as the degradation of these two polymers. The two types of plastics were tested in the form of pellets placed in contact with water samples collected from the Billings Reservoir, which is one of the largest and most important water reservoirs in the Metropolitan Region of São Paulo, Brazil. Certain parts of the reservoir are polluted with chemicals and metals by domestic and industrial sewage and, for 
this reason, only the Taquecetuba and Riacho Grande distributaries are used for water supply. Fishing is a popular recreational activity in this area because of the abundance of fish, such as tilapia, lambari, Hungarian carp, and traíras. Consequently, the presence of polymer substances such as BPA in the Billings Reservoir may be an important public health issue.

\section{Materials and methods}

\section{Polymeric materials}

For this study, PLA (Ingeo 3801-X, lot 653-89-01) was obtained from Cargill Agricola S.A. (São Paulo, SP, Brazil), and granulated isotactic homo-polypropylene $\mathrm{H} 603$ (density $0.905{\mathrm{~g} . \mathrm{cm}^{-3}}^{-3}$ and melt flow index $1.5 \mathrm{~g} / 10 \mathrm{~min}$.) was supplied by Europol (Brazil). BPA (analytical grade, 99.9\%) was purchased from Sigma-Aldrich. The incorporation of BPA into PP and PLA was performed using xylene and chloroform as solvents, respectively.

\section{Analysis of plastic materials}

Thermogravimetric analyses (TGA) were performed on a Perkin Elmer STA 6000 analyzer at a heating rate of $10^{\circ} \mathrm{Cmin}^{-1}$ from 25 to $600^{\circ} \mathrm{C}$ under a nitrogen atmosphere. Fourier transform infrared (FTIR) spectra were recorded on a Perkin Elmer Frontier 94942 spectrometer by applying a scanning range of 500 to $4000 \mathrm{~cm}^{-1}$ and 64 scans, using thin polymer films.

\section{Analysis of surface water samples}

The surface water samples used in the tests were collected in August 2015 from the Billings Reservoir using Van Dorn bottles. The variables water temperature; dissolved oxygen, electrical conductivity, and $\mathrm{pH}$ were measured in the field using an Oakton PCD 650 multiparameter probe. In the laboratory, the primary nutrient contents (nitrogen, phosphorus, and potassium), ${ }^{14}$ total Kjeldahl and ammoniacal nitrogen, ${ }^{15}$ and nitrite and nitrate contents ${ }^{16}$ were determined.

\section{Determination of BPA}

A high performance liquid chromatography (HPLC) method was developed for the determination of BPA according to the validation parameters proposed by Snyder et al. ${ }^{17}$ An Agilent 1220 HPLC-diode array detection (DAD) apparatus was used, equipped with automatic injector, column oven, Open LAB v. A.01.05 data acquisition software, and Phenomenex kinetex C18 column $(30 \mathrm{~mm} 2.1 \mathrm{~mm} \times 5 \mu \mathrm{m})$. The parameters of the method were isocratic mode of separation, mobile phase 50:50 (v/v) water acidified with orthophosphoric acid (PA, LabSynth, final $\mathrm{pH}=3.0,3 \mathrm{mmol} \mathrm{L}^{-1} \mathrm{H}_{3} \mathrm{PO}_{4}$ ) and acetonitrile (HPLC grade, JT Baker), flow rate of $1 \mathrm{~mL} \mathrm{~min}^{-1}$, injection volume of $5 \mu \mathrm{L}$, and readings at $\lambda=228 \mathrm{~nm}$. A $100 \mathrm{mg} \mathrm{L}^{-1}$ BPA stock solution was prepared with acetonitrile, and, after subsequent dilutions, a calibration curve was plotted with concentrations between $5 \mathrm{mg} \mathrm{L}^{-1}$ and $100 \mathrm{mg} \mathrm{L}^{-1}$ in order to evaluate the linearity of the method. Limits of quantification and detection were determined by analyzing the standard deviation of the response $(\sigma)$ and the slope of the curve $(\mathrm{S})$, in a ratio of $3.3 \sigma \mathrm{S}^{-1}$ for detection and $10 \sigma \mathrm{S}^{-1}$ for quantification. Caffeine (aqueous solution, Agilent) and diethylstilbestrol (99.9\%, Sigma-Aldrich) standards were used to verify the method's selectivity and specificity. The precision of the method (repeatability and reproducibility) was assessed by analyzing the intra-assay and inter-assay variance coefficients. In order to study the degradation process of BPA-containing PP and PLA in surface waters, tests were performed as described below.

The water samples collected from the reservoir had their $\mathrm{pH}$ adjusted to 7.5 using $0.1 \mathrm{~mol} \mathrm{~L}^{-1} \mathrm{NaOH}$ (Synth). Then, $100 \mathrm{~mL}$ of the samples was added to glass flasks, which were placed in a water bath at $23^{\circ} \mathrm{C}, 53^{\circ} \mathrm{C}$, or $83^{\circ} \mathrm{C}$, in triplicate. Subsequently, $0.5 \mathrm{~g}$ of PLA incorporated with BPA (PLA-BPA) was added to each flask. After $1 \mathrm{~min}$, a $1 \mathrm{~mL}$ aliquot was collected and filtered through a $0.45 \mu \mathrm{m}$ membrane using a glass syringe. Immediately after sample collection, the flasks were capped and returned to the water bath. Additional aliquots were collected from each flask daily for 8 days and analyzed using the HPLC method developed for BPA determination. To evaluate the release of BPA from PP, $50 \mathrm{~mL}$ of the collected water samples with $\mathrm{pH}$ adjusted to 7.5 and approximately $0.1 \mathrm{~g}$ of PP incorporated with BPA (PP-BPA) were added to glass flasks, in triplicate. The flasks were placed in a water bath under the same temperatures used in the PLA assays. After $1 \mathrm{~min}, 1 \mathrm{~mL}$ aliquots were withdrawn from each flask and filtered through a $0.45 \mu \mathrm{m}$ membrane using a glass syringe. Additional aliquots were withdrawn after $48 \mathrm{~h}, 72 \mathrm{~h}$, and 7 days and analyzed using the HPLC method developed for BPA determination.

\section{Results and discussion}

\section{Analysis of plastic materials}

Figure 1 shows the FTIR spectra and TGA curves of PLA, PLABPA, PP, and PP-BPA samples. Regarding PLA, Figure 1A shows FTIR spectra expanded between $500-4000 \mathrm{~cm}^{-1}$. The characteristic peaks of PLA occur between 1180 and $1745 \mathrm{~cm}^{-1} .{ }^{18}$ Peaks at $1033 \mathrm{~cm}^{-1}$, $1045 \mathrm{~cm}^{-1}$, and $1160 \mathrm{~cm}^{-1}$ correspond to the stretching of C-O bonds of aromatic ethers present in the PLA structure. The $1312 \mathrm{~cm}^{-1}$ band refers to the methyl group of PLA, and the peak of C-C bond is found at $1541 \mathrm{~cm}^{-1}$. Between 1720 and $1740 \mathrm{~cm}^{-1}$, a $\mathrm{C}=\mathrm{O}$ band that corresponds to aldehydes ${ }^{18}$ was identified at $1734 \mathrm{~cm}^{-1}$. Bands at 2329, 2852, and $2919 \mathrm{~cm}^{-1}$ correspond to the $\mathrm{C}-\mathrm{H}$ aliphatic bonds. The vibrational band at $2360 \mathrm{~cm}^{-1}$ refers to the presence of atmospheric $\mathrm{CO}_{2}$, and the peaks at 2850 and $2921 \mathrm{~cm}^{-1}$ probably correspond to asymmetric $\mathrm{C}-\mathrm{H}$ stretching of residual carbons. Regarding PP, Figure 1A shows FTIR spectra expanded between $1370-1390 \mathrm{~cm}^{-1}$. The peak at $1375 \mathrm{~cm}^{-1}$ corresponds to the angular deformation caused by the methyl bond. Bands between 1430 and $1470 \mathrm{~cm}^{-1}$ refer to the $\mathrm{CH}_{2}$ functional group present in the PP structure, whereas $\mathrm{C}-\mathrm{H}$ bonds caused peaks at 2836 and $2952 \mathrm{~cm}^{-1}$. The characteristic band of PP occurs between 2700 and $3000 \mathrm{~cm}^{-1} .{ }^{19}$ The characteristic FTIR peaks of PP-BPA occur above $3000 \mathrm{~cm}^{-1}$. Our results showed a peak at $3726 \mathrm{~cm}^{-1}$, corresponding to the $\mathrm{O}-\mathrm{H}$ bond of BPA, proving its presence in the material. The peak at $1542 \mathrm{~cm}^{-1}$ corresponds to the $\mathrm{C}=\mathrm{C}$ bond of aromatic rings of the BPA molecular structure. Peaks between 2852 and $2919 \mathrm{~cm}^{-1}$ were attributed to the $\mathrm{C}-\mathrm{H}$ functional group present in the polypropylene structure, similar to the results reported by Nikje et al. ${ }^{20}$

The incorporation of BPA into PLA caused the disappearance of the 1045 and $1160 \mathrm{~cm}^{-1}$ peaks, referring to the $\mathrm{C}-\mathrm{C}$ and $\mathrm{C}-\mathrm{O}$ bonds. With respect to PP, the incorporation of BPA caused the disappearance of the peaks 996,1375 , and $1460 \mathrm{~cm}^{-1}$, which correspond to the C-C, $\mathrm{CH}_{3}$, and $\mathrm{CH}_{2}$ bonds, respectively. These results show the interaction of BPA with the polymers. Figure 1B shows the TGA curves describing the behavior of PLA and PP at different temperatures. For PLA, there was no mass loss up to $300^{\circ} \mathrm{C}$. PLA degradation occurred in a single stage at $430^{\circ} \mathrm{C}$, contrary to the results reported by Zhang et al. ${ }^{21}$ in which PLA degradation occurred at approximately $400^{\circ} \mathrm{C}$ using a heating rate of $10^{\circ} \mathrm{C} / \mathrm{min}$ in an $\mathrm{N}_{2}$ atmosphere. The TGA 
curve describing the behavior of PLA-BPA is similar to that of pure PLA; the differences are given by the initial mass loss, which occurs at slightly lower temperatures (at approximately $426^{\circ} \mathrm{C}$ ), possibly because of the thermal characteristic of BPA, which degrades at temperatures in the range of $150^{\circ} \mathrm{C}$. This result suggests that there is some interaction between BPA and PLA, probably due to the polarity of PLA and the hydroxyl groups of BPA, which prompts a sudden and rapid separation of BPA from PLA at temperatures above $426^{\circ} \mathrm{C}$. The PP TGA curve in Figure 1B shows that mass loss started only at $360^{\circ} \mathrm{C}$ and that polymer degradation occurred at approximately $482^{\circ} \mathrm{C}$, differently from the results of Pérez et al..$^{22}$ in which degradation of PP occurred at approximately $450^{\circ} \mathrm{C}$, demonstrating a better thermal stability than pure PLA, promoted by the same heating rate condition at $10^{\circ} \mathrm{C} \mathrm{\text {min}^{-1 }}$ under $\mathrm{N}_{2}$ atmosphere. The TGA curves of PP-BPA and pure PP showed a similar mass loss due to the good mixing of the components. The degradation of PP-BPA began in the range of $480^{\circ} \mathrm{C}$, and PP-BPA and pure PP curves showed that degradation took place until $600^{\circ} \mathrm{C}$.

\section{Analysis of surface water samples}

The results of the analysis of surface water samples were as follows: electrical conductivity of $307.0 \mu \mathrm{S} \mathrm{cm} \mathrm{cm}^{-1}, \mathrm{pH}$ ranging from 7.8 to 8.4 , and maximum total phosphorus concentrations of $740.0 \mu \mathrm{g}$ $\mathrm{L}^{-1}$. The high nutrient load found in the selected sampling points of the Billings Reservoir, especially the total phosphorus content, allows the classification of these waters as hypereutrophic, according to the criteria proposed by Cunha et al. ${ }^{23}$ for tropical and subtropical lake systems. This trophic state was also observed in previous studies performed in different distributaries of the Billings Reservoir. ${ }^{24,25}$ According to Yang et al. ${ }^{26}$ this trophic condition is quite common in shallow reservoirs due to the high vulnerability of these ecosystems to anthropogenic interventions. Under these conditions, the salinity of water increases, which can facilitate the leaching of BPA from both PP and PLA.

\section{HPLC Analysis}

The HPLC method validated and applied for BPA analyses, presented limits of detection and quantification of $0.360 \mathrm{mgL}^{-1}$ and $1.09 \mathrm{mgL}^{-1}$, respectively. Values calculated based on the signal-tonoise ratio based on the standard curve $\left(y=2.2548 \times 10^{5} x+2.19469\right.$ $\left.; r^{2}=0.99451\right)$ suggest that the detection system is suitable for the analyses performed. The figures of merit, repeatability and reproducibility, determined using the concentration values of the analytical curve, returned $\% \mathrm{CV}$ (coefficient of variance) values of 1.5 to $3.9 \%$, respectively, which are excellent results, as the analysis employed complex environmental samples. In Figure 2, it is possible to observe that PP rapidly released BPA into the medium under the experimental conditions used and that PLA took longer to release BPA into the medium. This occurs because PLA has oxygen in its chemical structure, which makes it more polar and increases the strength of its interaction with BPA through van der Walls interactions. This finding corroborates the decrease in the immediate estrogenic activity that BPA would have if released immediately under normal $\mathrm{pH}$ conditions of surface water. ${ }^{27}$
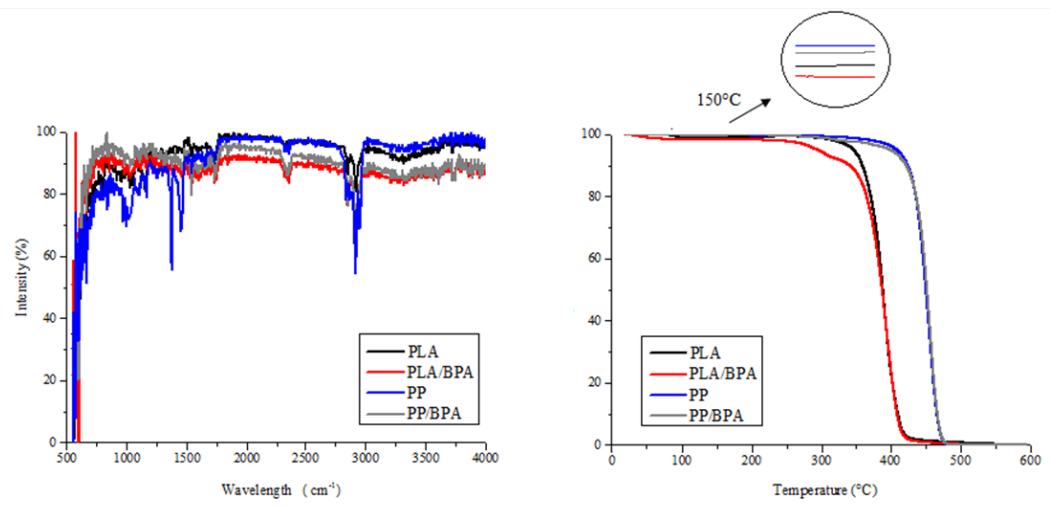

Figure I (A) FTIR spectra and (B) TGA curves of PLA, PLA-BPA, PP, and PP-BPA samples.

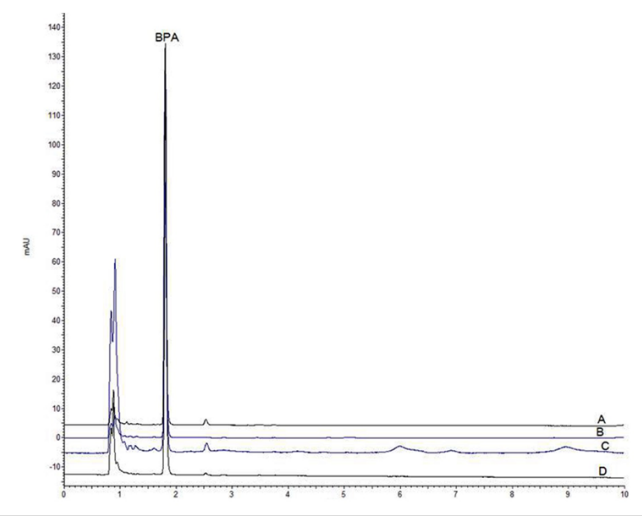

Figure 2 Chromatogram of (A) PP-BPA at $83^{\circ} \mathrm{C}$ and $48 \mathrm{~h}$, (B) PLA-BPA at $83^{\circ} \mathrm{C}$ and $48 \mathrm{~h}$, (C) PLA-BPA at $83^{\circ} \mathrm{C}$ and $0 \mathrm{~h}$, (D) PLA-BPA at $83^{\circ} \mathrm{C}$ and $0 \mathrm{~h}$ using acetonitrile: acidified water $(50: 50, v / v)$ as the mobile phase, injection volume of $5 \mu \mathrm{L}$, detection at $228 \mathrm{~nm}, 40^{\circ} \mathrm{C}$, and flow rate of $\mathrm{ImL} \mathrm{min}{ }^{-1}$. Graph showing

BPA release from PP and PLA at different temperatures. 


\section{Conclusion}

The results show that there is greater interaction between BPA and PLA than between BPA and PP. TGA results further confirm this observation. The interaction probably occurs due to the polarity of PLA and the presence of hydroxyl groups in BPA. PP-based plastics release BPA more rapidly into surface waters than PLA-based plastics. The validated HPLC method is suitable for verifying that polymeric materials containing BPA can be a leaching source of BPA in surface waters. The presence of dissolved BPA in surface waters at sufficient concentrations could cause estrogenic-related impacts on aquatic life as well as humans, exposed through the consumption of drinking water, especially considering that the studied water reservoir receives a large amount of plastic waste and since traditional water treatment can not eliminate residues of these materials it is necessary that we have methodologies to verify the quantity of these substances in the treated water that will go to the residences of the population

\section{Acknowledgements}

The authors Derval dos Santos Rosa and Elizabete Campos de Lima are grateful to UFABC (grant no. 447180/2014-2), FAPESP (grant no. 306401/2013-4), and CNPq (no. 2013/12559-8) for their financial support.

\section{Conflict of interest}

The authors declare there is no conflict of interest.

\section{References}

1. Fu, Keng YC, Yi HC, et al. Probabilistic integrated risk assessment of human exposure risk to environmental bisphenol A pollution sources. Environ Sci Pollut Res. 2016;23(19):19897-19910.

2. Bila DM, Dezotti M. Desreguladores endócrinos no meio ambiente: efeitos e consequências. Química Nova. 2007;30(3):651-666.

3. Wallace E, Flint S, Markle T, et al. Bisphenol A exposure, effects, and policy: A wildlife perspective. $J$ of Environ Management. 2010;104:19-34.

4. Witorsch RJ. Endocrine disruptors: can biological effects and environmental Risks be predicted?. Regul Toxicol Pharmacol. 2002;36(1):118-130.

5. Dodds EC, Lawson W. Synthetic estrogenic agents without the phenanthrenenucleus. Nature. 1936;3476(137):996.

6. Acconia F, Pallotini V, Marino M. Molecular Mechanisms of Action of BPA. Dose-Response. 2015;13(4)1-9.

7. Careghini A, Mastorgio AF, Saponaro S, et al. Bisphenol A, nonylphenols, benzophenones, and benzotriazoles in soils, groundwater, surface water, sediments, and food: a review. Environ Sci Pollut Res Int. 2015;22(8):5711-5741.

8. Krishnan AV, Stathis P, Permuth SF, et al. Bisphenol-A: an estrogenic substance is released from polycarbonate flasks during autoclaving, Endocrinology. 1993;132(6):2279-2286.

9. HU XL, Peng JF, Jiang GB, et al. Evaluating the impacts of some environmentally relevant factors on the availability of bisphenol-A with Negligible-depletion SPME. Chemosphere. 2006;65(11):1935-1941.
10. Brooks BW, Corrales J, Kristofco LA, et al. Global Assessment of Bisphenol A in the Environment: Review and Analysis of Its Occurrence and Bioaccumulation. Dose-Response: an International Journal. 2015;13(3):1-29.

11. Chun YS, Jung HC, Han MS, et al. Crystallization behavior and rheological properties of polycarbonate and polypropylene blends. Polym Eng Sci. 1999;39:2304-2312.

12. Phuong VT, Gigante V, Aliotta L, et al. Reactively extruded ecocomposites based on poly(lactic acid)/bisphenol A polycarbonate blends reinforced with regenerated cellulose microfibers. Composites Science and Technology. 2017;139:127-137.

13. Bhunia K, Sablani SS, Tang J, et al. Migration of chemical compounds from packaging polymers during microwave, conventional heat treatment, and storage. Comprehensive Reviews in Food Science and Food Safety. 2013;12(5):523-545.

14. APHA. Standard Methods for the Examination of Water and Wastewater. 21st ed. Washington: Byrd Prepress Springfield; 2005.

15. APHA. Standard Methods for the Examination of Water and Wastewater. 22nd ed. Washington: APHA; 2012.

16. ASTM. Manual on Industrial Water and Industrial Wastewater. STP 70B. Philadelphia: American Society of Testing and Materials (ASTM). 1981.

17. Snyder LR, Kirkland JJ, Glajch JL. Practical HPLC Method Development. New Jersey: Wiley; 1997.

18. Hoidy HW, Ahmad BM, AL-Mulla JA. Preparation and Characterization of Polylactic Acid/Polycaprolactone Clay Nanocomposites. Journal of Applied Sciences. 2010;10(2):97-106.

19. Carvalho XMG, Mansur SH, Vasconcelos LW, et al. Obtenção de Compósitos de Resíduos de Ardósia e Polipropileno. Polímeros: Ciência e Tecnologia. 2007;17(2):98-103.

20. Nikje MM, Alavi, Askarzadeh M. Green and Inexpensive Method to Recover Bisphenol-A from Polycarbonate Wastes. Polímeros. 2013;23(1):29-31.

21. Pérez R. Polypropylene/starch blends. Study of thermal and morphological properties. Journal of Chilean Chemical Society. 2013;58(1):1643-1646.

22. Cunha DG, Calijuri MC, Lamparelli MC. A trophic state index for tropical/subtropical reservoirs $\left(\mathrm{TSI}_{\mathrm{ts}}\right)$. Ecological Engineering. 2013;60:126-134.

23. Marian. Biota and water quality in the Riacho Grande reservoir, Billings Complex (São Paulo, Brazil). Acta Limnol Bras. 2006;18(3):267-280.

24. Moschini-Carlos. Cyanobacteria and Cyanotoxin in the Billings Reservoir (São Paulo, SP, Brazil). Limnética. 2009;28(2):273-282.

25. Yang J. Algae community and trophic state of subtropical reservoirs in southeast Fujian, China. Environmental Science Pollution Research. 2012;19(5):1432-1442.

26. Zhang J, Luo JD, Tong L. et al. The dependence of pyrolysis behavior on the crystal state of cellulose. Carbohyd Polym. 2010;79(1):164-169.

27. ICH. International Conference on harmonization of technical requirements of pharmaceuticals for human use, ICH Harmonized Tripartite Guideline, Validation of Analytical Procedures: Text and Methodology. ICH Harmonized Tripartite Guideline. 2005;1-17. 